\title{
Forecasting saline intrusion under the influence of the northeast monsoon in the Mekong Delta
}

\author{
Nguyen Van Hong ${ }^{1 *}$, Nguyen Thao Hien ${ }^{1}$, Nguyen Thi Thanh Minh ${ }^{1}$, Ho Cong Toan ${ }^{1}$ \\ ${ }^{1}$ Sub-Institute of Hydrometeorology and Climate Change; \\ nguyenvanhong79@gmail.com; nthien2710@gmail.com; minhmminh0419@gmail.com; \\ hocongtoanhdh@gmail.com;
}

*Correspondence: nguyenvanhong79@gmail.com; Tel: +84-913613206

Received: 05 September 2021; Accepted: 03 October 2021; Published: 25 December 2021

\begin{abstract}
Saline intrusion is one of the most frequently occurring natural disasters in a coastal area, posing the most serious impact in the Vietnamese Mekong Delta (MD). With the characteristics of the region as an open and low system, located at the end of the Mekong River basin and part of the Vam Co River system, this region is strongly affected by the tidal regime, and therefore saline intrusion is a feature of the region and has become familiar to the people living here in the dry season. The degree of deep penetration into the inland area depends on several factors. These factors contribute to the determination of the depth of salinity penetration into the MD. Therefore, the paper will focus on the 3 factors having the greatest impacts on the salinity penetration, including the influence of upstream flow, high tide, and the northeast monsoon season in the application of a combined assessment model to forecast saline intrusion in 2021 in the Mekong Delta. The reliability of the salinity propagation module is greater than $0.7 \%$, based on the data series observed and calculated daily for 3 months during the dry season. The location of the measuring stations from the estuary to the inland field is about $20-50 \mathrm{~km}$, showing a suitable range to calculate the salinity forecast to support livelihood models in the Mekong River.
\end{abstract}

Keywords: Saline intrusion; Upstream flow; Tide; Southeast wind; Vietnamese Mekong Delta.

\section{Introduction}

The saline intrusion in the Mekong Delta (MD) has caused several disadvantages to water sources for production and people's life, in the context of flourishing development of hydropower plants on the Mekong mainstream with higher intensity and frequency due to climate change (CC) [1]. The MD has a flat-hollow-open-low terrain with a ground elevation of $2 \mathrm{~m}$ lower than the sea level, under the influence of uneven semidiurnal tidal regimes in the East Sea and diurnal tidal regimes in the West Sea [2-4]. In addition, the MD is also located in the active monsoon region. Especially during the northeast monsoon with the prevailing direction of the east-southeast, the water source at the upstream of the Mekong River flowing to the downstream at the lowest level, together with the wind direction parallel to the estuaries, resulting in the tide level rise and causing the deeper saline intrusion into the river [5].

Serious saline intrusion in MD in 1977, 1993, 1998, 2005, and 2010 caused heavy damage to the economy, society, and environment. Especially, there have been 2 times of historical saline intrusion with the earlier occurrence and deeper intrusion in the river and canal system [6] in the last 5 years. Notably, a salinity limit of $4 \mathrm{~g} / \mathrm{l}$ can approach as deep as 
80 kilometers into the main rivers, leading to $10 / 13$ provinces affected by saltwater in 2016 . By 2020 , a salinity limit of $4 \mathrm{~g} / \mathrm{l}$ can approach as deep as approximately $100 \mathrm{~km}$ inland, an increase compared to the same period in 2016, causing damage to the coastal provinces up to 100,000 ha of productive land and about 95 households are in lack of freshwater [7-10]. It can be seen that the occurrence of the last two historical events in a short period has been clear evidence of the increasing severity of saline intrusion in the MD.

Studies on calculation or forecasts and early warning of salinity intrusion in the MD are quite abundant. These studies have evaluated the combined impacts of climate change and the rapid development of an upstream hydropower dam system, with the variation of precipitation, sea-level rise, and upstream flows. These studies are approached with different methods such as (a) hydrological models to assess salinity concentrations in river basins $[3,8,15,16]$; (b) hydrodynamic modeling and combination with meteorological and tidal forecast models, to clarify salinity intrusion and hydraulic regime in the estuaries [2]; (c) using deep learning method based on artificial neural network platform [17-18], in the MD, publications on this issue are rather scarce in general. In addition, the study [21] proposed a method different from the above methods for early warning of saline intrusion in the MD, which is a simple linear seasonal forecasting model based on ENSO and SSI (standardized streamflow index) predictors. With a dense river network and many irrigation works, while input data and computational capacity are limits, hence the one-dimensional model has been widely used for the study area, considered as a feasible method to apply flow simulation and saline intrusion for the entire river system in the MD [15].

For example, recent studies on simulating and forecasting saline intrusion in the MD may be cited [11], has applied modeling (MIKE 11-MIKE11 GIS) to calculate and forecasted salinity based on Google Earth software at coastal stations and upstream flow fluctuations at Tan Chau, Chau Doc stations. The model is currently serving forecasting work at the National Center for Hydrometeorological Forecasting. Another study [12] has built a tool to assess the socio-economic effects of saline intrusion to estimate the damage caused by the saltwater intrusion on people, economy, and society with the historical salinity event in 2016 for 4 provinces (Ca Mau, Bac Lieu, Kien Giang, Soc Trang, Ben Tre), the level of visual impact is shown on a map and calculated by the exposure, hazard and vulnerability functions based on human objects using water in production, aquaculture and cultivation.

With international cooperation studies on the harmful effects of saltwater intrusion and solutions for the MD region, [13] has analyzed data on perceptions of the adverse impacts of salinity intrusion on rice farming, through the process of interviewing households and workers to investigate the people's understanding of the extent and how to respond to natural disasters, to give recommendations and solutions to the increasing saltwater intrusion in the MD. For the study [14] has calculated the Socio-ecological resilience of mangrove-shrimp models under various threats exacerbated from salinity intrusion in the coastal area. This study utilized a Motivation and Ability framework in combination with a sustainable livelihood framework to measure the perceived values and resilience of mangrove-shrimp farming systems, based on a broad interview with farmers, scientists.

Summarizing the latest articles related to the problem in the MD, saline intrusion is one of the types of natural disasters that have a terrific and strong impact on people's lives and perceptions. Since then, it has led to studies from basic to advanced levels on the evolution of saline intrusion to its damage potential and measures to adapt to its increase over time. Simultaneously, the studies also provide pilot models of livelihoods for improving people's material and spiritual lives in response to saline intrusion and lack of freshwater.

However, at present, there are no specific studies on the northeast monsoon or other bases to forecast or have a warning of the extent and speed of wind impacting the saline intrusion. Thus, it is very necessary and essential to forecast the impact of saline intrusion 
in the MD quickly and accurately. In this study, the authors will focus on analysis and evaluation of the process of salinity transmission in the main rivers, under the influence of the upstream flows and tidal regime in combination with the northeast monsoon with mathematical modeling method.

\section{Materials and methods}

\subsection{Study area}

\subsubsection{Advantages}

The MD is located at the end of the Mekong River basin with an area of over 39,000 $\mathrm{km}^{2}$, accounting for $79 \%$ of the delta area and equal to $5 \%$ of the Mekong River basin area. The MD has a large system of rivers and canals, including the Tien and Hau river systems, the Vam Co river system, the Cai Lon-Cai Be river system, the Giang Thanh River, and many other tributaries and canals (Figure 1). Geographical location and natural conditions not only create advantages in irrigation and drainage for agriculture, industry, fishery, and forestry, etc. But also play an important role in transportation for economic and social activities. The MD is located in the humid \& tropical, sub-equatorial monsoon area, favorable for the development and diversification of crops and livestock. Several valuable aquatic species can be cultivated in the coastal areas which are affected by saline intrusion [1-4].

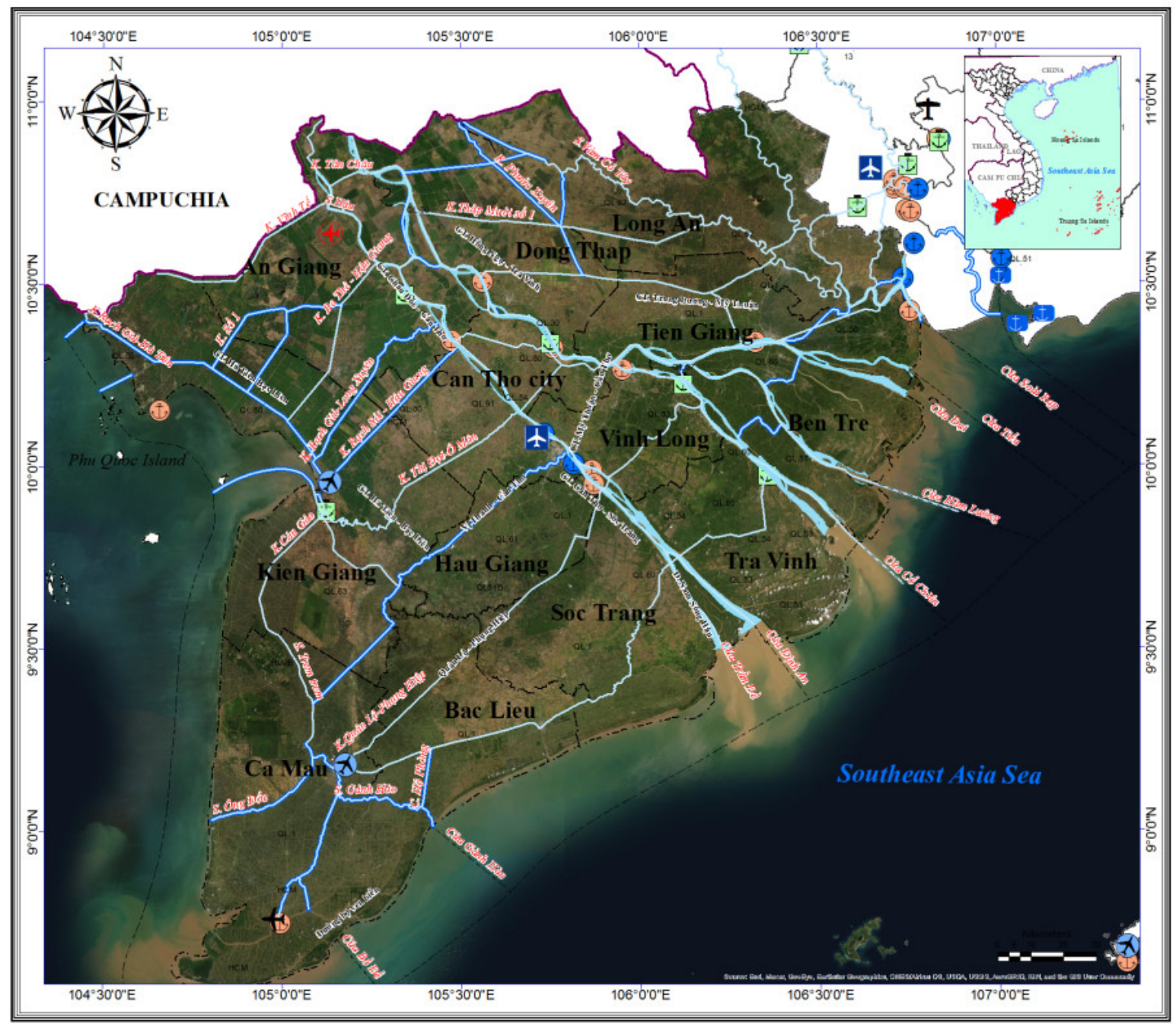

Figure 1. The Mekong Delta region. 


\subsubsection{Disadvantages}

Two important upstream factors affecting water resources in the MD are the amount of water stored in TonleSap, which helps to regulate and limit flood flows in the MD during the flood season and increases the water source in the dry season; and the flow to the Kratie station (at the beginning of the MD) which is located about $300 \mathrm{~km}$ upstream from the Vietnam-Cambodia border, representing the starting point of the lower Mekong River [19].

Depending on the above conditions, there are great changes in the flow to the delta in nature, the change could be from a tendency to flow naturally to being regulated in both the flood and dry seasons. While the large floods become less frequent, the number of the small and medium floods increases and floodplains in the upper delta become "eager and eager for the flood", leading to a lack of mud and sand in the MD for sedimentation, the lack of water to push salt back into the sea; making the saline intrusion more and more complicated to be forecasted. The northeast wind can become a negative factor in the lives of the residents in the MD.

\subsection{Setup hydrodynamic and advection-dispersion models}

MIKE 11 model, a mathematical model, is used in this study as the main method. MIKE 11 is a one-dimensional unsteady flow modeling for the detailed analysis, design, management, and operation of both simple and complex river and channel systems. In the MIKE 11 model, the river/channel flow process is calculated based on the Saint Venant Equations that are solved by the Abbott-Ionescu six-point implicit difference method. This model and MIKE Zero have been applied widely in several types of research and projects in Vietnam. Besides, the MIKE 11 model set is also used in annual forecasting at the SubInstitute of Hydrometeorology and Climate Change.

In this study, two modules in MIKE 11 (i.e. Hydrodynamic (HD) and Advection Dispersion (AD) modules) were applied to simulate and forecast the saline intrusion in the MD. The methodological framework in this study is described in Figure 2, including the data collection step, calculation scenarios, model reliability assessment, and the impacts on the increase of saline intrusion and transmission in the MD.

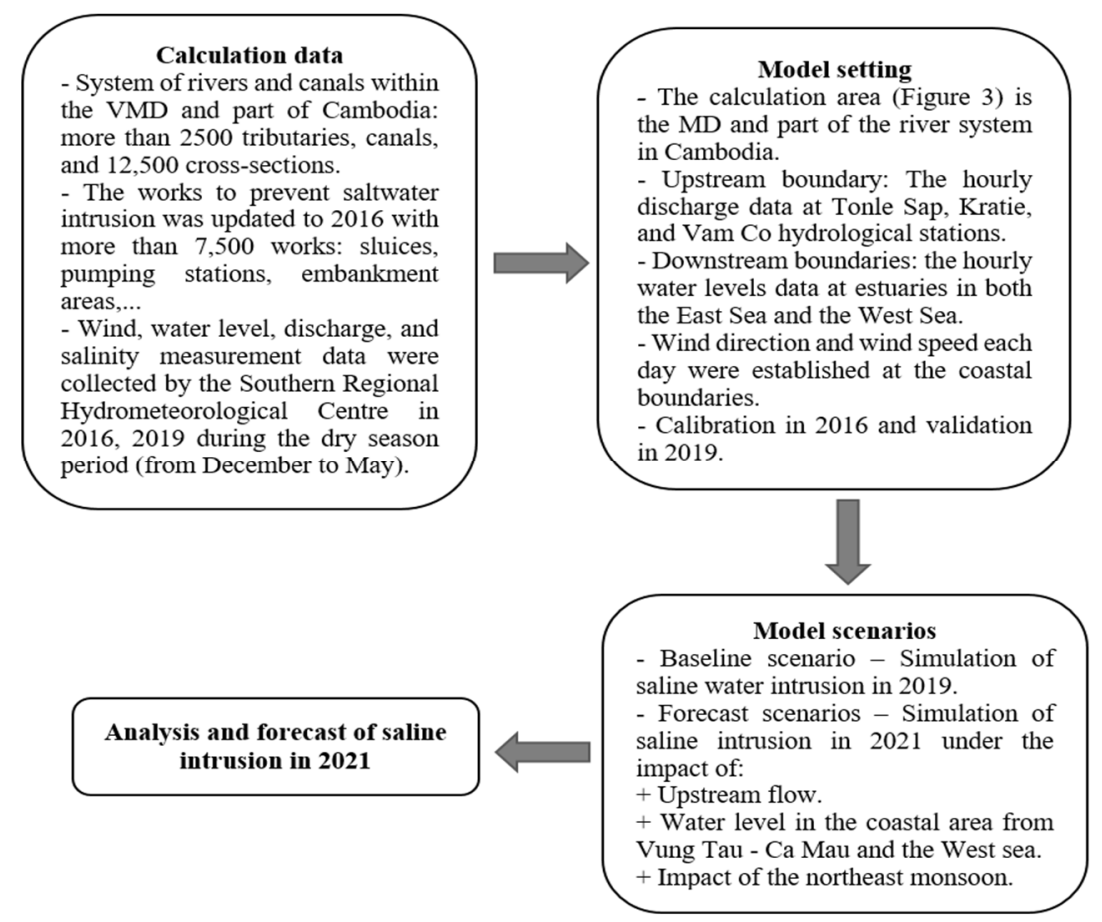

Figure 2. The methodological framework for salinity forecast. 
The MD and part of the river system in Cambodia with more than 2,500 tributaries, canals, and 12,500 cross-sections are the area for calculation. There are more than 7,500 works, including the culverts, pumping stations, embankment areas as of 2016.

Boundary data for the model:

- Flow boundaries at Tonle Sap, Kratie and Vam Co;

- Tidal level boundaries at tributaries in both East Sea and West Sea;

- The parameters showing wind direction and wind speed at the coastal boundaries.

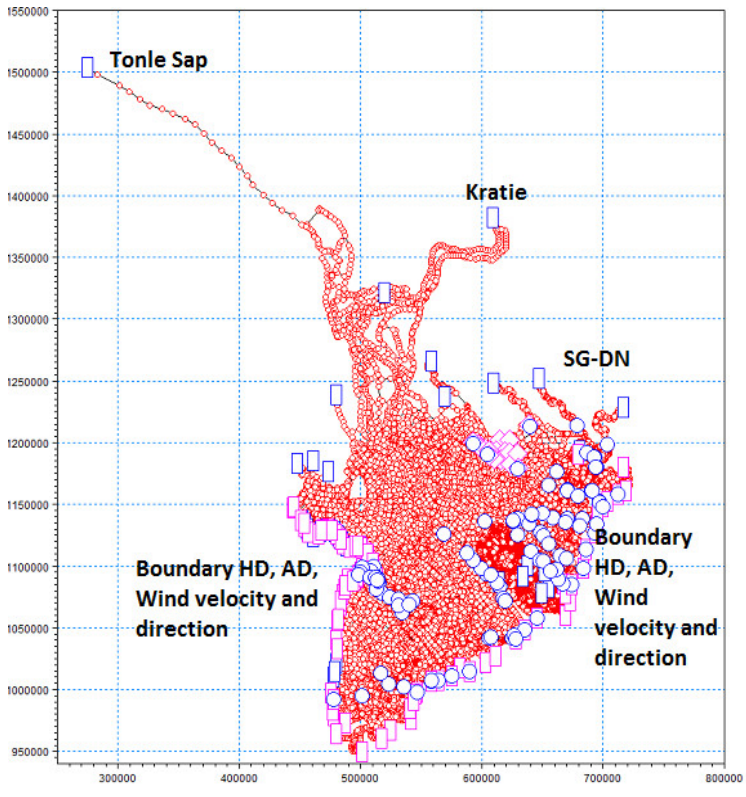

Figure 3. River network in modeling saline intrusion: including boundaries and hydrological stations.

\subsection{Data acquisition for forecast scenarios in 2021}

The salinity in the MD depends on many factors such as a) the water flow upstream of the Mekong River, b) the volume of water accumulated from the flood season of the previous year and rainfall, c) the tidal regime in combination with the northeast wind and d) the groundwater extraction for production and daily life [4].

This task is applied to a mathematical model in consideration of the factors causing the significant increase in the salinity over time in river basins, showing the process of the river-sea interaction, the complexity of river flows, tides, and meteorological conditions in the dry season.

\section{a) Upstream flow}

Two upstream factors that significantly affect freshwater reserves and saline intrusion in the lower MD are the water stored in Tonle Sap and the flow at the Kratie station. According to the statistical report updated to April 2016 by the Southern Institute of Water Resources Research, the evolution of water in Tonle Sap (Figurea) is extremely low (about $1.23 \mathrm{~m}$ on average) compared with the average data series from 1980 to 2031, and this was lower than an average level of $0.69 \mathrm{~m}$ at the same period in 2014-2015. As can be seen, the flow of Tonle Sap to the Delta is extremely limited [24].

The annual flow at the Kratie station (Figureb) was very low from the beginning of the dry season until March started to increase from the end of the month to the beginning of April, and remained stable. It can be seen that the serious shortage of fresh water occurs when the saline intrusion approaches inland the deepest. According to the data series of the flow path in Kratie for the period 1980-2016, there are fluctuations in a certain value range at the time of the driest month of the year [24]. 
Flow material was collected in 2011, 2012, 2013, 2016, and 2019 at Kraite station. The boundary-value of the two upstream locations is the average flow of the years, thereby determining the forecast flow and calculating saltwater intrusion for the dry season of 2021.

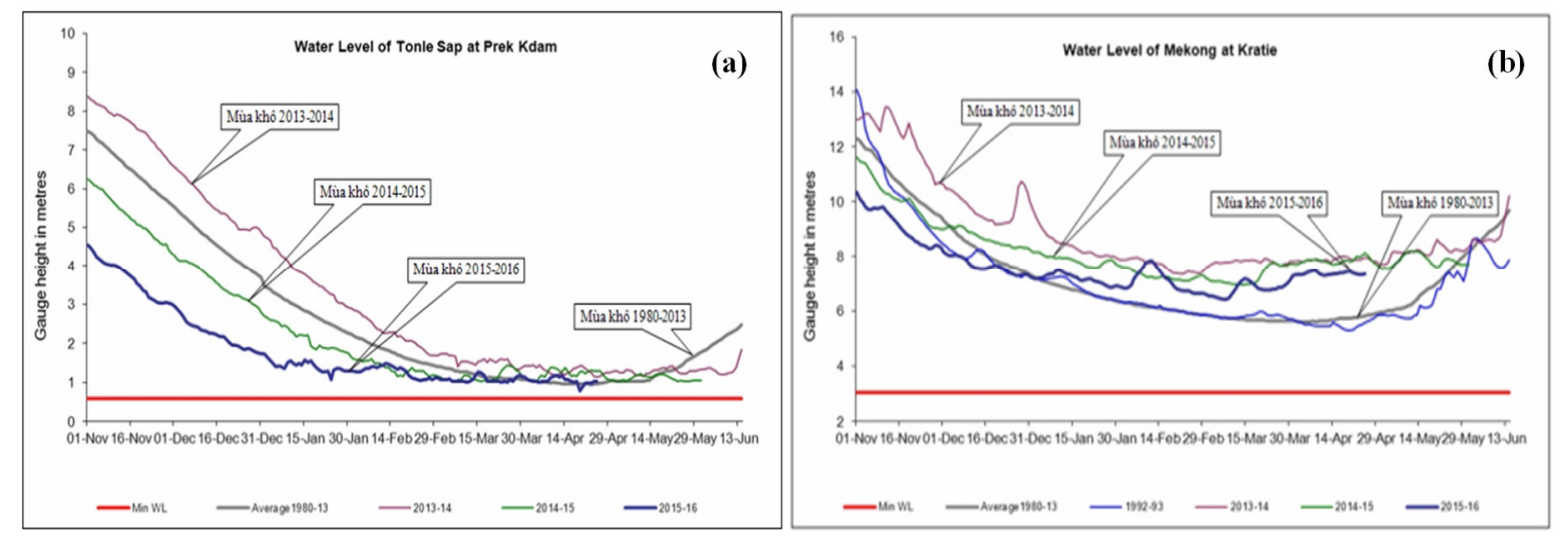

Figure 4. Daily discharges in the upper Mekong River over the years: a) The water level in the dry season 1980-2016 of Tonle Sap; b) The water level in the dry season 1980-2016 at Kratie station.

\section{b) Forecasting the water level}

To forecast the coastal tide level, the U-Tide calculation software by analyzing the harmonic constant set is applied to this task. "U-Tide consists of a pair of Matlab functions designed to be easy to understand and implement: ut_solv: for analysis in two-dimensions (e.g., tidal currents) and one-dimension (e.g. sea level); ut reconstr: to use the analysis results for reconstruction of a time sequence for a hind-cast or forecast/prediction if needed" [22]. The software has become widely accepted in the study of physical oceanography. The results of the water level forecast at estuary stations in the Southern region using U-TIDE are shown in Figure.
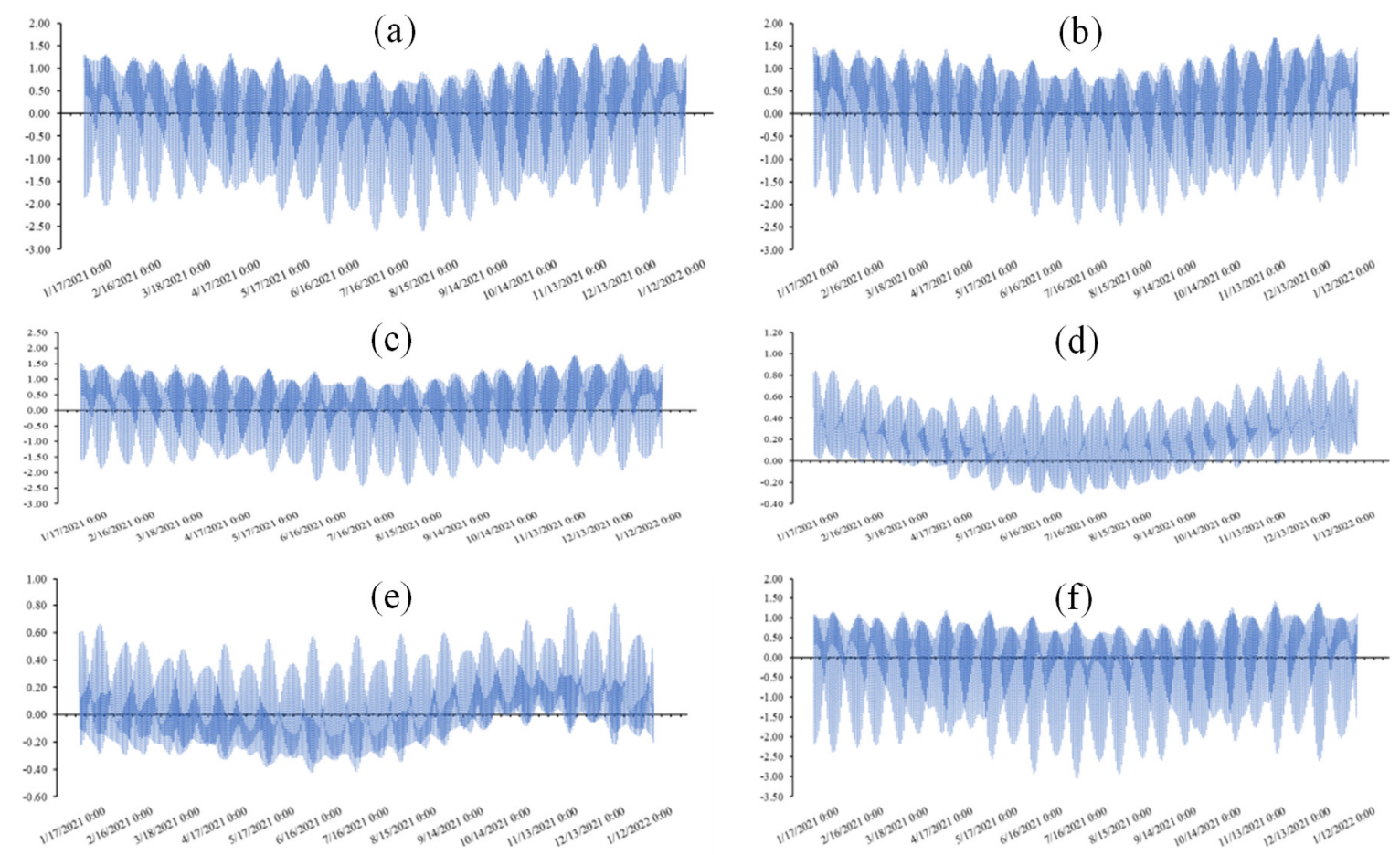

Figure 5. Forecasted water levels in 2021 at coastal stations in the Southern region: (a) Vam Kenh; (b) An Thuan; (c) Ben Trai; (d) Song Doc; (e) Rach Gia; (f) Vung Tau.

Tide peaks can reach over $1.5 \mathrm{~m}$ starting in early January and ending in late March. 
Table 1. Forecasted high and low tides at coastal stations in the Southern region from January to March 2021.

\begin{tabular}{|c|c|c|c|c|c|c|c|c|c|}
\hline \multirow[b]{2}{*}{$\begin{array}{l}\text { Name of } \\
\text { station }\end{array}$} & \multirow[b]{2}{*}{ Highest day } & \multicolumn{4}{|c|}{ High tide } & \multicolumn{4}{|c|}{ Low tide } \\
\hline & & $\mathbf{H}(\mathbf{m})$ & $\begin{array}{c}\text { Hour } \\
\text { xh }\end{array}$ & $\begin{array}{c}\mathbf{H} \\
(\mathbf{m})\end{array}$ & $\begin{array}{c}\text { Hour } \\
\text { xh }\end{array}$ & $\mathbf{H}(\mathrm{m})$ & Hour xh & $\mathbf{H}(\mathbf{m})$ & $\begin{array}{c}\text { Hour } \\
\text { xh }\end{array}$ \\
\hline Vam Kenh & $\begin{array}{c}\text { February } 31, \\
2021\end{array}$ & 1.34 & $5: 00$ & 1.19 & $17: 00$ & -1.17 & $11: 00$ & -1.4 & $23: 00$ \\
\hline An Thuan & $\begin{array}{c}\text { February } 3, \\
2021\end{array}$ & 1.42 & $5: 00$ & 1.23 & $18: 00$ & -1.48 & $12: 00$ & -0.71 & 23:00 \\
\hline Ben Trai & $\begin{array}{c}\text { February } 3, \\
2021\end{array}$ & 1.46 & $5: 00$ & 1.27 & $18: 00$ & -1.46 & $12: 00$ & -0.48 & 23:00 \\
\hline Song Doc & $\begin{array}{c}\text { January } 14, \\
2021\end{array}$ & 0.85 & 4:00 & & & 0.04 & $11: 00$ & & \\
\hline Rach Gia & $\begin{array}{c}\text { January } 14 \\
2021\end{array}$ & 0.66 & $5: 00$ & 0.15 & $17: 00$ & -0.13 & 13:00 & -0.28 & 22:00 \\
\hline Vung Tau & $\begin{array}{c}\text { February } 3, \\
2021\end{array}$ & 1.14 & $4: 00$ & 1.01 & $17: 00$ & -1.84 & $11: 00$ & -1.02 & 23:00 \\
\hline
\end{tabular}

\section{c) The northeast monsoon wind}

In the middle and late months of the dry season in the MD, wind components with a direction from Northeast to Southeast often appear, most notably the wind with Southeast direction, which raises the water level, contributing to the transfer of salinity inland, affecting agricultural production, which is called "Gio Chuong". This type of wind is formed from the Asian continent's high pressure in the East Sea and the development and expansion of the Pacific subtropical high pressure to the west. Specifically, from 5 a.m. to 12 p.m., the prevailing wind direction between East and East-Northeast roughly coincides with the wind direction at sea. From 2 p.m. to 2 a.m., influenced by sea-continental winds, the main wind direction will be Southeast [5].

In the Southern region, at the beginning of the season, the wind only accounts for 20 $30 \%$ of all windy days, but this rate gradually increases and by February, the rate will account for $73 \%$. Under the influence of "Gio Chuong", all wind levels can exceed the level of over $5-6 \mathrm{~m} / \mathrm{s}$ (the level of wind obstruction affects saline intrusion).

The wind charts (Figure 6, Figure 7) as follows show characteristics of wind direction and speed in the northeast monsoon time (from February to April) at Soc Trang and My Tho stations in 2015 and 2016.

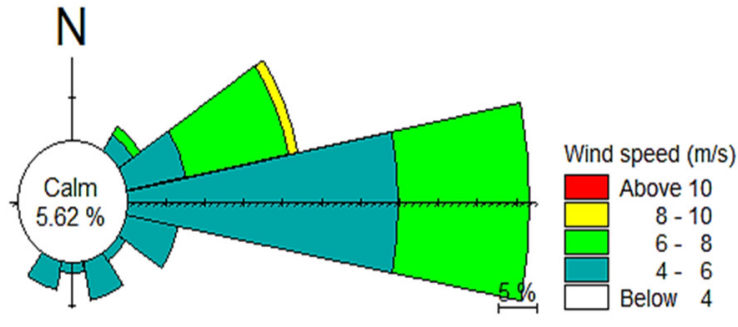

(a)

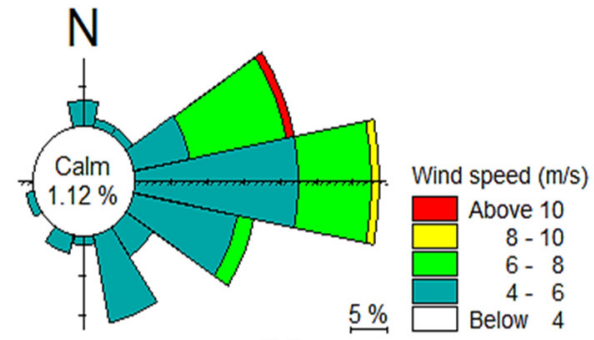

(b)

Figure 6. Wind charts at Soc Trang station in the dry season in 2015 (a) and 2016 (b).

It is shown in the wind chart of the Soc Trang station that the prevailing wind direction in 2015 is from the East and East-Northeast (Figure). By 2016, the wind direction blowing from the southeast appears more with a frequency of $15 \%$. Therefore, it can be assumed that the wind direction blowing from the East-Southeast may cause disadvantages and increase the salinity in coastal areas such as Tran De, Dinh An (Hau river), My Thanh river (Soc Trang province). 


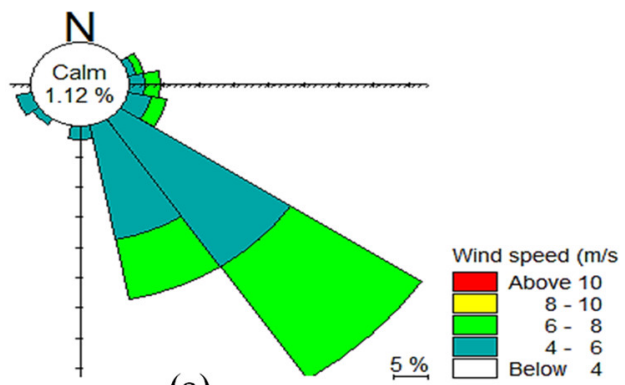

(a)

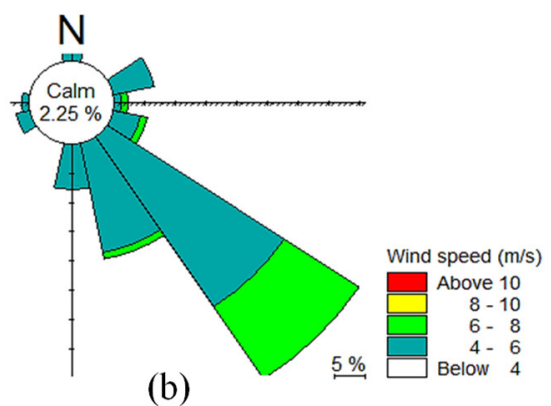

(b)

Figure 7. Wind charts at My Tho station in the dry season in 2015 (left) and 2016 (right).

Based on the wind chart at My Tho station over the years 2015 and 2016 (Figure), the prevailing wind direction is the Southeast direction with the direction perpendicular to the estuary cross-section at major tributaries such as Tien and Co Chien rivers, Ba Lai, Ham Luong River, and Vam Co river systems with common wind speeds of 4-8 m/s.

The northeast monsoon is one of the specific meteorological factors that cause many disadvantages to freshwater sources in the MD. To forecast saline intrusion most effectively, it is necessary to include the influencing factors in the saline simulation. Although it occurs every year and is considered a typical feature of the region, there is no software model to forecast it or quantify its morphological trends. As the result, the wind data in 2016 shall be used to forecast, due to the similarity between the wind direction blowing at My Tho and Soc Trang stations.

\section{Results and discussion}

\subsection{Model calibration and validation}

Based on the data after 2012: the Saline intrusion in the MD estuaries tends to be about 1 a month earlier than in the previous period; salinity has been affected since late December of the previous year in the year with the low flow, and can reach the highest salinity from February to mid-March; and tend to decrease rapidly from the end of March because of the increase in the low flows thanks to the flow regulation at the upstream. The maximum salinity limit of $4 \mathrm{~g} / \mathrm{l}$ in the dry season can approach more than $70 \mathrm{~km}$; In the past, it could only approach $60 \mathrm{~km}$ in years of high salinity in several estuaries, now it occurs more often [3]. Therefore, the data used for calibration \& validation is calculated from February to April. The final results of salinity concentration at various stations are presented in Table 2.

Table 2. Results of salinity testing at the Mekong Delta stations.

\begin{tabular}{|c|c|c|}
\hline \multirow{3}{*}{$\begin{array}{l}\text { The proposed options to } \\
\text { calculate the salinity } \\
\text { transmission, are: } \\
\text { - Adjusting the salinity } \\
\text { value on an hourly basis of } \\
\text { February 2016; } \\
\text { - Testing with the highest } \\
\text { salinity value of the day }\end{array}$} & The MD river basin & Saigon-Dong Nai River basin \\
\hline & \begin{tabular}{|r|r|}
2 & \\
1.8 & \\
1.6 & \\
1.4 & \\
1.2 & \\
1 & \\
0.8 & \\
0.6 & \\
0.4 & \\
0.2 & \\
\end{tabular} & \\
\hline & $\begin{array}{c}\text { My Hoa Station }- \text { Ham Luong river } \\
\text { NSE }=0.681\end{array}$ & $\begin{array}{c}\text { Tan An Station -Vam Co river } \\
\text { NSE }=0.62\end{array}$ \\
\hline
\end{tabular}




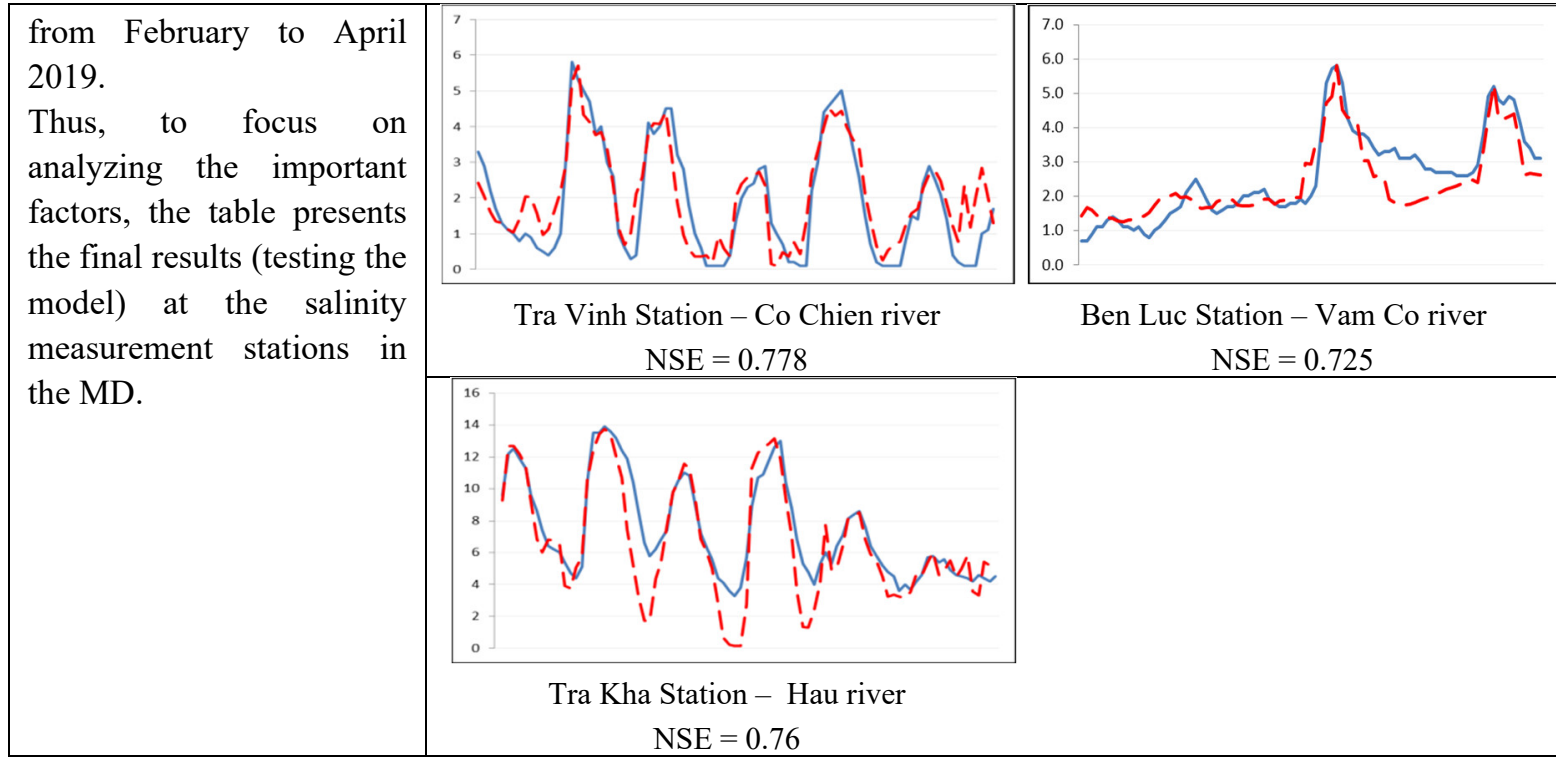

According to the simulation results of salinity at the MD estuaries, in the dry season of 2019, the salinity came earlier from the beginning of December last year and reached the highest salinity in February and March, then gradually decreased. Compared to the 2016 period, the level of salinity difference between the measuring stations is much more significant. In Vam Co rivers, the salinity rate in 2016 was 5\%o higher than in 2019 at each station. Particularly for the MD rivers, the difference in salinity concentration is obvious (5-10\%). Especially for large rivers (Tien River, Hau River) with large and wide estuaries, flat terrains along with other factors have made saltwater intruded deeper into the inland. Therefore, to forecast saline intrusion for the main river systems in the MD, it is necessary to consider the negative factors causing more saline intrusion.
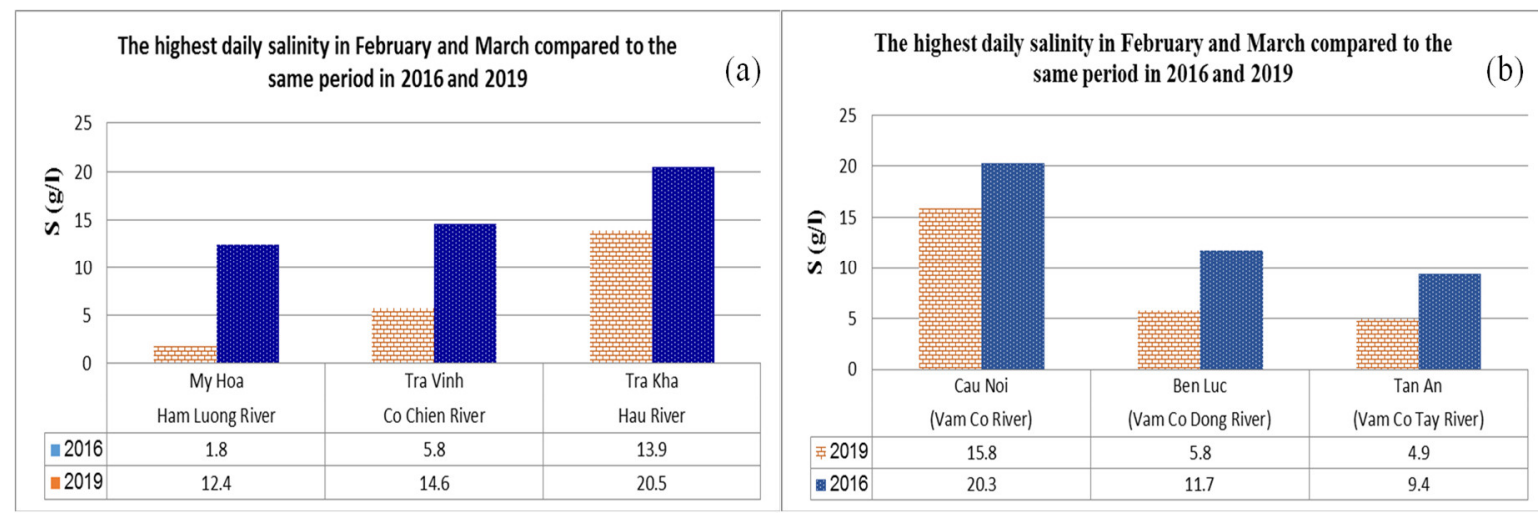

Figure 8. Maximum daily salinity concentrations from February to March 2016 and 2019: (a) The MD river basin; (b) Saigon-Dong Nai river basin.

Results and discussion: According to the assessment results in the graph of the salinity process at the MD salinity measurement stations, the index presents the reliability and accuracy of the model parameters in application in the forecast and have warning on the saline intrusion in the main rivers of the MD such as Hau River, Tien River, Vam Co, Co Chien, Ham Luong, etc. At the same time, the salinity assessment chart at 6 stations (Figure) has also shown the impact of natural factors on the extent of salinity penetration, salinity magnitude, and time of occurrence in the inland area. Therefore, it is necessary to study and include in the forecasting process the influence of negative factors on the formation of salinity to forecast the saline intrusion for the main river systems of the MD provinces. 


\subsection{Forecasting results}

The average flow in the dry season tends to decrease. In recent years, there have been changes in the time of occurrence of the highest water level: the average tidal peak in the last 10 years is about $2-6 \mathrm{~cm}$ higher than the average of several years.

The trend of saline intrusion in the MD will be more complicated and the MD will have to cope with the saline intrusion and "eager for flooding" in the lower Mekong as shown in the forecast table of salinity values from February to April 2021 (Table 3) and the map of the maximum salinity in the dry season in 2021 (Figure). Among 13 provinces in the MD, there are 9 ones subject to the impacts of the saline intrusion. Especially the red area, it is forecasted that $\mathrm{Ca} \mathrm{Mau}$ and the West Sea will have the highest salinity from 15$25 \%$ according to the map. The estuaries are subject to the influence of the northeast wind such as Tran De, Dinh An, Dai, Tieu, and Thi Vai river, etc., belonging to the main rivers such as Hau, Tien, and Vam Co river will have good conditions for saline intrusion into the inland. In coastal provinces and provinces along major rivers such as Tra Vinh, Soc Trang, Vinh Long, Ben Tre, and Long An, the salinity is forecast at 10-25\%o.

With increased and prolonged salinity, saline intrusion will affect the mangrove ecosystem along with the sea level rise, which has risks causing negative impacts on the vegetation and biodiversity of Melaleuca forest ecosystems in coastal provinces such as $\mathrm{Ca}$ Mau, Kien Giang, etc.

THE FORECASTED HIGHTED SALINITY MAP AT THE MEKONG DELTA REGION IN 2021

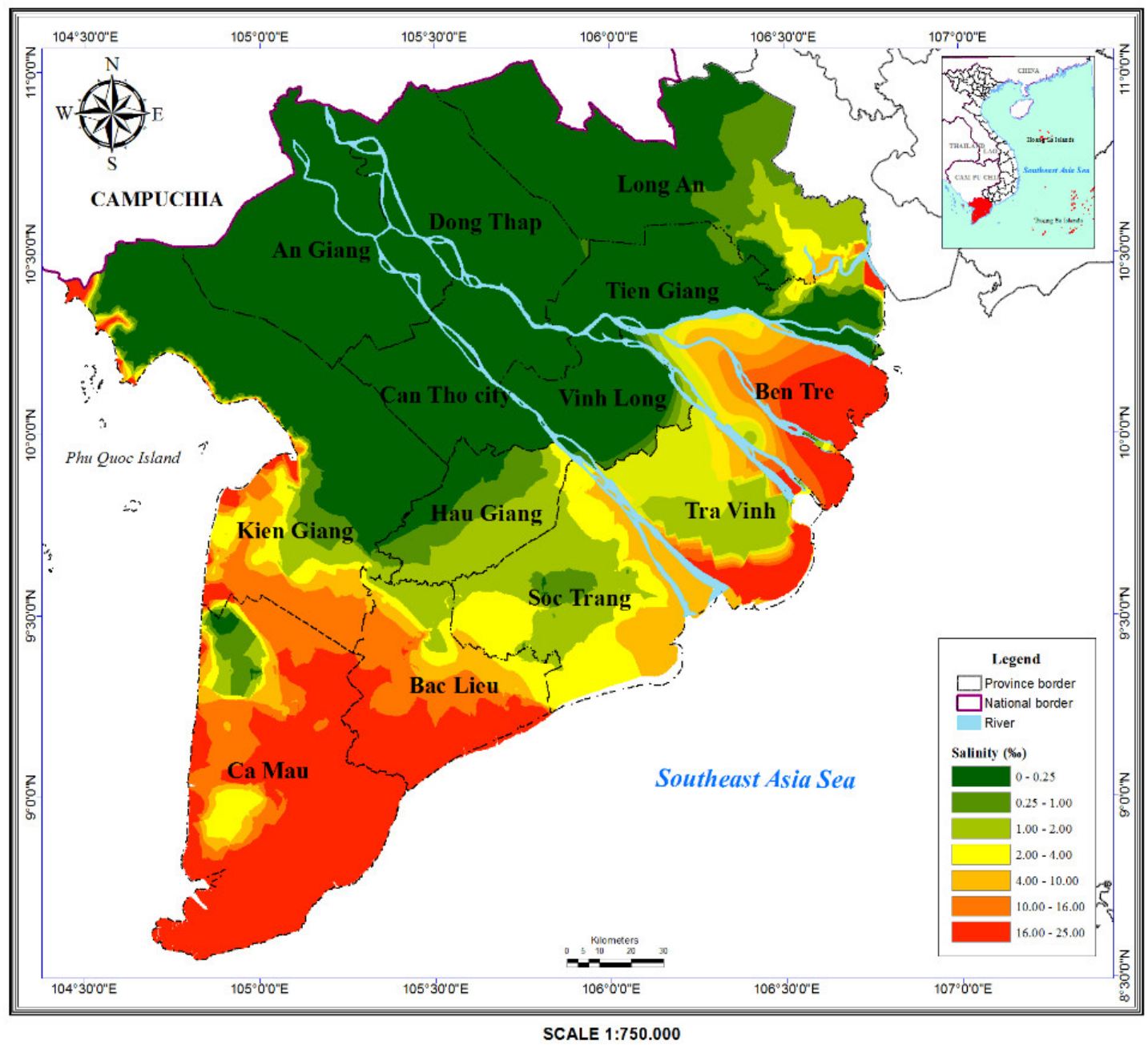

Figure 9. The forecasted highest salinity in 2021. 
Table 3. Forecast of the highest salinity range from February to April 2021 at hydrological stations in the MD.

\begin{tabular}{|c|c|c|c|c|c|}
\hline \multirow{2}{*}{ No. } & \multirow{2}{*}{$\begin{array}{c}\text { Name of the } \\
\text { station }\end{array}$} & \multirow{2}{*}{ River } & \multicolumn{3}{|c|}{ The highest salinity range (\%o) } \\
\hline & & & February & March & April \\
\hline 1 & Bnh Dai & Cua Dai & $24-26$ & $24-26$ & $22-24$ \\
\hline 2 & My Hoa & Ham Luong & $8-10$ & $7-9$ & $9-11$ \\
\hline 3 & Tra Vinh & Co Chien & $14-16$ & $9-11$ & $14-16$ \\
\hline 4 & Ben Trai & Co Chien & $24-26$ & $21-23$ & $20-22$ \\
\hline 5 & Dai Ngai & Hau & $14-16$ & $10-12$ & $15-17$ \\
\hline 6 & Tra Kha & Hau & $23-25$ & $25-27$ & $21-23$ \\
\hline 7 & Tran De & $\mathrm{Hau}$ & $25-27$ & $25-27$ & $21-23$ \\
\hline 8 & $\mathrm{Ca} \mathrm{Mau}$ & Ganh Hao & $27-29$ & $25-27$ & $27-29$ \\
\hline 9 & Xeo Ro & Cai Lon & $18-20$ & $18-20$ & $14-16$ \\
\hline 10 & Rach Gia & Bien Tay & $15-17$ & $23-25$ & $24-26$ \\
\hline 11 & Ben Luc & Vam Co Dong & $5-6$ & $7-8$ & $4-6$ \\
\hline 12 & Cau Noi & Vam Co & $12-14$ & $15-17$ & $14-16$ \\
\hline
\end{tabular}

Based on the measured and predicted salinity results in April 2021 (Table 3 and Figure), it is revealed that:

In the Vam Co river system, the measured salinity is all within the forecast range, such as Ben Luc station with the measured salinity value of $4.8 \%$, which is consistent with the forecast range of 4-6\%. At Cau Noi station, the measured salinity is $16.8 \%$, corresponding to the forecasted salinity in the range of $14-16 \%$.

In the MD river system, the results at the estuary and inland salinity measurement stations are as follows:

+ At coastal stations: Tran De station and Xeo Ro station with measured salinity of $22.4 \%$ and $13.8 \%$ respectively, both stations are within the predicted value; Binh Dai station has a measured salinity higher than the forecasted value of $0.5 \%$; Ben Trai station with measured salinity is $16.4 \%$, smaller than the forecasted value of $3 \%$.

+ Regarding the inland stations, the predicted salinity tends to be higher than the measured value from 3-6\%. In particular, My Hoa station has measured salinity of 6.3\%o ($3 \%$ ); Dai Ngai station has measured salinity of 7.3\% (-6\%o), and Ca Mau station has measured salinity of 34.5\% (+5\%o). ("-" Smaller value; "+": value larger than the forecast range).

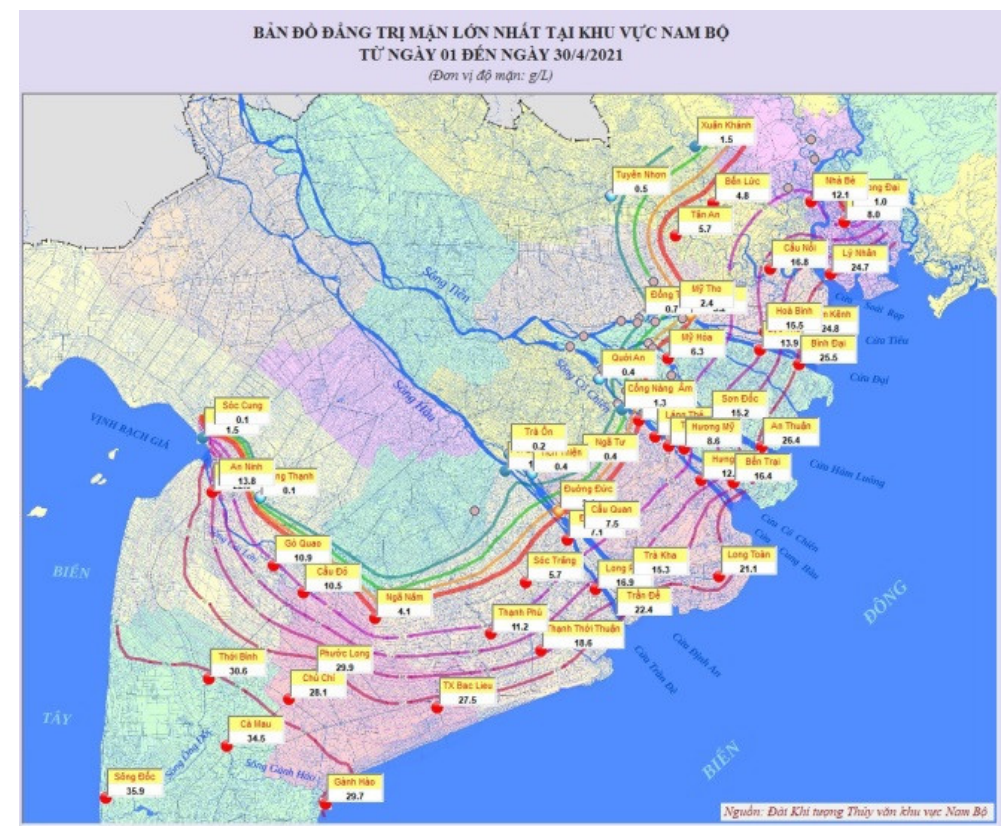

Figure 10. Map of the max salinity contour in the Southern region from April 1 to 30, 2021 (Southern Regional Hydrometeorological Centre). 
According to the results of analysis and assessment of saline intrusion, the monthly salinity forecast value based on the salinity trends in the Vam Co river system, Rach Gia, and Cua Tran De areas is more consistent with the measured values. In the inland area, forecasts of salinity are still limited due to the complexity of the canal system and saltwater-prevention sluices,... but the deviation is incurable and can be improved thanks to the long-term monitoring and adjustment of the model closer to reality and continuously forecasting in the conditions of climate change and sea-level rise in the MD.

\section{Conclusion}

The integrated model is applied in the paper for saline intrusion forecast in the Mekong Delta and Saigon-Dong Nai River. From the results of water level verification at hydrological stations and the U-tide model, it is indicated that the model parameters are appropriate for tidal prediction simulation for the study area.

Thus, the forecast results will support providing early warning information for people and local authorities to adjust the cultivation schedule, propose solutions to limit the situation of saline intrusion affecting' lives of residents.

However, the study of factors influencing saline intrusion in the MD remains limited. Especially the flow from the upstream Mekong River. This factor necessitates a long-term research complex because of the climate change of the current period and is influenced by inter-reservoir regulation upstream. Application of this study, the authors desire to operate the annual saline forecasting model to better adjust the model parameters and achieve the best results for the livelihood of the population in the MD.

Author contribution statement: Conceptualization and methodology: Hong. V.N., Hien. T.N.; validation, formal analysis: Minh. T.T.N.; investigation and project administration: Hien. T.N., Toan. C.H.; resources, data curation, software, draft: Hong. V.N., Hien .T.N.; preparation and writing-original: Hong. V.N., Hien. T.N., Minh. T.T.N. writing-review, and editing, visualization: Hong. V.N., Hien. T.N., Toan. C.H. All authors have read and agreed to the published version of the manuscript.

Acknowledgments: This research is completed in the program of regular assignment by the functions of the Sub-Institute of Hydrometeorology and Climate Change in 2021, specifically Task 9: "Forecasting tides and saline intrusion in the main rivers of the Southern region".

Competing interest statement: The authors declare no conflict of interest.

\section{Reference}

1. Binh, D.V.; Kantoush, S.; Sumi, T.; Mai, N.T.; Trung, L.V. Study on the impacts of river-damming and climate change on the Mekong Delta of Vietnam. Disaster Prev. Res. Inst. Annuals 2017, 60(B), 804-826.

2. Duong, T.A.; Bui, M.D.; Rutschmann, P. Impact of Climate Change on Salinity Intrusion in the Mekong Delta. Presented at the $14^{\text {th }}$ International Conference on Environmental Science and Technology (CEST2015), Rhodes, Greece, 2015.

3. Dat, T.Q.; Likitdecharote, K.; Srisatit, T.; Trung, N.H. Modeling The Influence of River Discharge and Sea Level Rise on Salinity Intrusion in Mekong Delta. In First Environment Asia International Conference on "Environmental Supporting in Food and Energy Security: Crisis and Opportunity", 2011, 685-701.

4. Tuan, T.V.; Thuong, T.V.; Phat, H.P.D.; Hung, D.N. Assessing the Combined Impacts of Dams Upstream, Climate Change, Drought, Tide, and Sea Level Rise on the Temporal Variation of Paddy Land in Tien Giang Province. IOP Conf. Ser. Earth Environ. Sci. 2019, 338.

5. Ba, L.H.; Drought, saline intrusion in the Mekong Delta: Theoretical and Practical 
Basis. Ho Chi Minh City National University Publishing House, 2017, pp. 525, ISBN: 978604735283.

6. Mai, N.P.; Kantoush, S.; Sumi, T.; Thang, T.D.; Trung, L.V.; Van Binh, D. Assessing and Adapting The Impacts of Dams Operation and Sea Level Rising on Saltwater Intrusions into The Vietnamese Mekong Delta. J. Jpn. Soc. Civ. Eng. Ser. B1, 2018, 74(5), I_373-I_378.

7. Dung, N.T.; Thuan, P.; Lan, N.T. Livelihoods of residents in drought-salt areas in the Mekong Delta - Situation and solutions. J. Political Sci. Inf. 2020, 4, 77-80.

8. Kantoush, S.; Binh, D.V.; Sumi, T.; Trung, L.V. Impact of Upstream Hydropower Dams and Climate Change on Hydrodynamics of Vietnamese Mekong Delta. Annu. J. Hydraul. Eng. JSCE 2017, 61, I_109-I_114.

9. Khang, D.K.; Kotera, A.; Sakamoto, T.; Yokozawa, M. Sensitivity of Salinity Intrusion to Sea Level Rise and River Flow Change in Vietnamese Mekong DeltaImpacts on Availability of Irrigation Water for Rice Cropping. J. Agric. Meteorol. 2008, 64, 167-176.

10. Le, T.N.; Tran, D.X.; Tran, T.V.; Gyeltshen, S.; Lam, T.V.; Luu, T.H.; Nguyen, D.Q.; Dao, T.V. Estimating Soil Water Susceptibility to Salinization in the Mekong River Delta Using a Modified DRASTIC Model. Water 2021, 13, 1636. https://doi.org/10.3390/w13121636.

11. Hai, Đ.V.; Hue, L.T.; Tri, D.Q. Researching and applying modeling software to forecast floods and saltwater intrusion in the Mekong River and display the results of saltwater forecasting on Google Earth. VN J. Hydrometeorol. 2020, 710, 33-42. https://doi.org/10.36335/VNJHM.2020(710).33-42.

12. University of Science and Vietnam Institute for Advanced Studies in Mathematics, develop a tool to assess the effects of saltwater intrusion on socio-economic and apply experimental properties to the Mekong Delta. J. Clim. Change Sci. 2021, 17(3), 21-29.

13. Tien, K.D.; Adam, L.; Micheal, D.Y. Perceptions and responses to rising salinity intrusion in the Mekong River Delta: What drives a long-term community-based strategy. Sci. Total Environ. 2020, 711, 134759.

14. Nguyen, H.Q.; Wyatt, A. Socio-ecological resilience of mangrove-shrimp models under various threats exacerbated from salinity intrusion in coastal area of the Vietnamese Mekong Delta. Int. J. Sustainable Dev. World Ecol. 2020, 27(7), 638651.

15. Hai, T.X.; Van Nghi, V.; Hung, V.H.; Tuan, D.N.; Lam, D.T.; Van, C.T. Assessing and Forecasting Saline Intrusion in the Vietnamese Mekong Delta Under The Impact of Upstream Flow and Sea Level Rise. J. Environ. Sci. Eng. B, 2019, 8, 174.

16. Toan, T.Q. Climate Change and Sea Level Rise in the Mekong Delta: Flood, Tidal Inundation, Salinity Intrusion, and Irrigation Adaptation Methods. Coastal Disasters and Climate Change in Vietnam: Engineering and Planning Perspectives, 2014, 199-217.

17. Roehl Jr, E.A.; Daamen, R.C.; Cook, J.B. Estimating seawater intrusion impacts on coastal intakes as a result of climate change. J. AWWA 2013, 105(11), E642-E650. https://doi.org/10.5942/jawwa.2013.105.0131.

18. Rohmer, J.; Brisset, N. Short-term forecasting of saltwater occurrence at La Comté River (French Guiana) using a kernel-based support vector machine. Environ. Earth Sci. 2017, 76, 246. https://doi.org/10.1007/s12665-017-6553-5.

19. Climate Change Adaptation Project for Sustainable Agriculture and Rural Development in the coastal provinces of the Mekong Delta in Vietnam. Southern Institute of Water Resources Planning, 2013.

20. Duyen, M.T.; Minh, N.M. Strengthen forecasting and warning of hydro- 
meteorological disasters in response to climate change, saline intrusion and sea level rise in the Mekong Delta. Environ. Magazine 2021, 4, 58-60.

21. Apel, H., Khiem, M., Quan, N.H. and Toan, T.Q. Brief Communication: Seasonal Prediction of Salinity Intrusion in The Mekong Delta. Nat. Hazards Earth Syst. Sci. 2020, 20(6), 1609-1616.

22. Codiga, D. L. Unified tidal analysis and prediction using the UTide Matlab functions, GSO Tech. Rep. Graduate School of Oceanography, Univ. of Rhode Island Narragansett, RI, 2011.

23. Southern Institute of Water Resources Research - Vietnam Academy for Water Resources, Investigating and forecasting the flood water levels inland and monitoring saline intrusion in the Mekong Delta in service of directing and operating agricultural production, 2019.

24. Southern Institute of Water Resources Research. The report "Forecasting saline intrusion at estuaries in the coastal area of the Mekong Delta and proposing solutions to combat drought", 2016. 